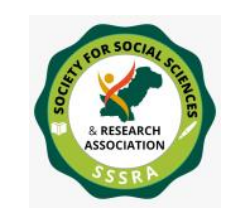

Hate Speeches on Twitter and Facebook ...

\title{
Hate Speeches on Twitter and Facebook in South Asia: A Case Study Of Malala Yousufzai
}

\author{
Saba Naz \\ Ph.D Scholar \\ Department of Mass Communication \\ University of Karachi \\ Sb.siddiquil@gmail.com \\ Dr. Muhammad Osama Shafiq \\ Assistant Professor \\ Department of Mass Communication \\ University of Karachi \\ osamashafiq@gmail.com
}

\begin{abstract}
:
Nowadays social media platforms have become a medium that allows people to post anything they wish. Since the time internet grew, a radical change has been discerned in society. With the emergence of social media sites, many challenges also thrived in the society that took the society into interesting and alarming ways altogether. As time is passing as technology is intensifying new forms of hate, abuse, bullying, and discrimination are also increasing in society. It can be said that digital technology is reshaping coercion based on caste, color, gender, race, culture, likes, dislikes. Many societies are concerned with this problem of growing hate speeches on social media but no proper barrier on these sites has been seen to prevent hate discourses. This study examined the attitudes of social media users including Facebook and Twitter over the incident of Noble Prize laureate Malala Yousufzai, a young activist who worked and spoke for the educational rights of girls who were born in Swat valley. She spoke against this erroneous system that didn't allow girls to gain education and became a prominent member of society at the little age of 14 . She was shot by Taliban and then a controversy started against her, some people admired her and she became a celebrity all over South Asia while an extreme amount of criticism was also seen against her incident.
\end{abstract}

Through this study, we aim to understand the abundance of hate speech on Facebook and Twitter in South Asia by using Qualitative and Quantitative Research Methods. For that purpose we took the case study method and provide a large-scale measurement and analysis of different hashtags used during the case of Malala on the social media 


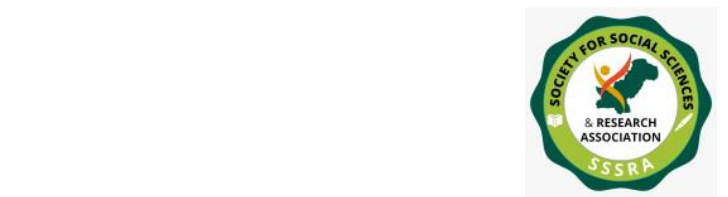

Hate Speeches on Twitter and Facebook ...

platform. To achieve the objective of our research, we amassed Tweets and Facebook posts posted since the year 2011 till now related to this case. This article identifies numerous forms of hate speeches on social media that are arising in South Asia and altering the minds of people using social media, it is also guiding how to abate hate speeches that are delivered on social media with particular hashtags on various incidents and matters. The collected data revealed that hate speech has become a social problem with substantial inimical effects in societies. This study explains that social media should be utilized to benefit mankind positively and gently.

\section{Keywords: Social Media, South Asia, Malala Yousufzai, Nobel Prize, NGO}

\section{Introduction:}

As we all know that apart from our daily lives these days social media has generated another life in our actual world. So many people love to share their thoughts mostly related to current affairs and the ongoing political scenario of their country. In this social networking life, various issues have been raised and among those issues, the problem of online hate speech has become a new factor that is continued from abstracts. Now people are using freedom of speech without any limitations (Enarsson \& Lindgren, 2019) . Hate speech is a statement intended to defame another person through the use of cruel and inferior language. It attacks a person based on various attributes such as religion, national origin, race, or gender identity. There has been a grand debate over freedom of speech and the deliverance of hate speeches by the platform of social media. (Abdullahi, 2019)

The issue of hate speech has touched a new dimension and it has been greatly observed in South Asia after Malala Yousufzai was targeted in Swat Valley. An overreaching question is why hate speeches are conveying under the name of freedom of speech. On social media, many people, incidents and issues have been subjected to discussion, debate, and hatred. This thing has also seen in the case study of Malala when the brutality of the Taliban shot Malala to stop education in Swat valley as she wished to attain knowledge and spread it in the valley and this incident became a topic to spread hate speech. (Biography, 2017) Protests were started to condemn the attack and to acquire women's right to procure education in South Asia. In the year 2012, she first time presented at United Nations and gave a speech there. She urged the leaders to give access and make it easy for girls to learn. She articulated the conditions of suffocated terrible occupied areas where the Taliban jeopardized people. (Their World, 2013)

She also co-founded an NGO and wrote several books on her path and its circumstances. One of her famous books that were her biography with the title of 'I am Malala' is still a 


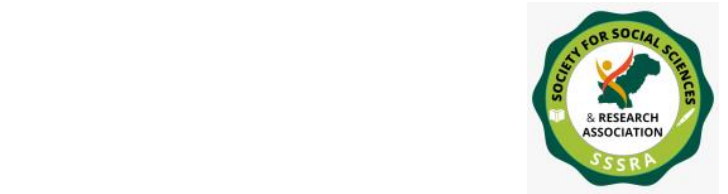

Hate Speeches on Twitter and Facebook ...

best seller. (Little, Brown and Company, 2017) At the very young age of 17, she received a Noble Prize. The UN Secretary-General announced to celebrate $12^{\text {th }}$ July her birthday as Malala Day in her gratitude and attempts to ensure education for all the children. (Blumberg, 2016) Malala showed that education is the fundamental right of every human being and she asserted it through her efforts but still there's a controversy on her whole incident. (Editors, 2018) People consumed that there's no such reality behind her incident because, no one can be this audacious at such small age. She and her father launched the Malala fund to give access to girls to gain a quality education. She also started a school for Syrian refugees in Lebanon. On every platform, she demanded to spend on education instead of other useless things. (Editors, 2018) In the year 2018, she returned to Pakistan after the 2012 attack. Even she was the one who was facing criticism since the time of her incident but when she returned, she endured the same thing. (Moolji, 2018) On one side people praised her and on the next hand, many people criticized her. Still, people have several beliefs about her both favorable and nasty. (Shah, 2013) Even an Indian movie was also made on her biography that got higher TRP named Gulmakai. (Jhunjhunwala, 2020) There's no absolute fact to disparage her but she's the one who has both kinds of fellowship positive and negative. After analyzing this case it can be said that how social media websites deliver into hate sites during a distinct moment or incident.

Twitter is a microblogging social networking website that allows people to share and update news and information with hashtags which are known as tweets and trends on Twitter. The sharing of hatred speech also causes extremism in the environment and threatens society's peace. Sometimes, these speeches provoke people to be violent and sometimes stop them to share their inner positivity, and then the democracy of the country also weakens. Jessica Rogers (2019) noted that the symbol hashtag gains popularity through Twitter. With the help of hashtags, the users can easily search their relevant content and in case any topic is trending then with help of a specific hashtag, all the discussions and debates can easily be found on Twitter.

In the year 2004, Facebook was also formed by Mark Zuckerberg with the assistance of his fellows. (Ahmed, 2018) As cited by TIMES (2010) Facebook was included in the list of 1000 websites and it came on the top of the list. The Facebook users were given the freedom to add or delete anything from their profiles and in this way, negative content also emerged on Facebook. In this study, we have so far analyzed some questions in hate speech monitoring including what was the actual hashtag used on Facebook and Twitter, how did the audience interact with the specific hashtag and posted hate or favorable content correlated with the hashtag and how did the user use his or her narrative to forward or disseminate information they attained from social media? 


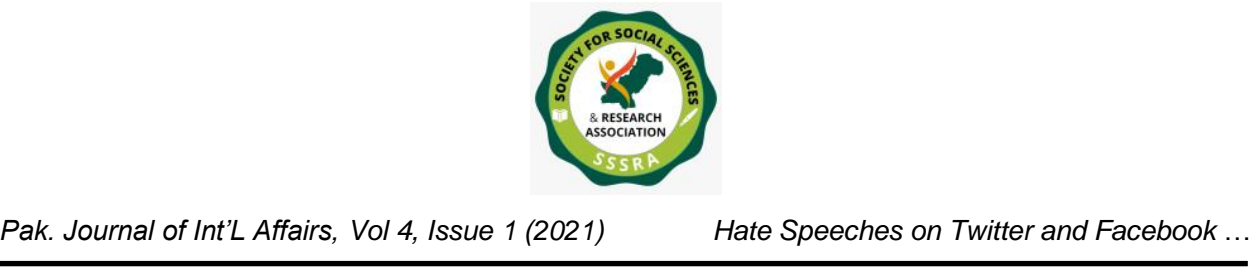

\section{Literature Review:}

Here are some reviews and related researches relate to the proposition of this research:

A Nigerian study expressed that the voters' choice of political candidates in Presidential Elections 2011 and 2015 in Nigeria was shaped by political communications through posts and tweets on social media. There are numerous online platforms and social media websites that expand extreme ideologies and their ratio is rapidly increasing. (Okoro \& Santas, 2017) Cyberhate, A Legal and Historical content Analysis of Extremists' Use of Computer Networks in America was done by Brian Levin. This study shows the usage of the internet and hates content on social media in the USA, it regulated the law for cybercrimes and hateful content. The study revealed that in the past nobody could pass hate speeches against anyone else in the USA but after the arrival of the Internet, it has been very common. It should have been protected after the first amendment in the USA constitution but many extremists and groups are using it for hate speeches so far. (Levin, 2002)

C. Udanor and Chinatu C. Anyanwu researched in 2019, to discover the ratio of hate speeches on Twitter in Nigeria. For this motive, they used a software called Python, in which an individual's attitude is interpreted. This experiment found that Twitter handles $65 \%$ of hate content in Nigeria, the researchers explained that neither Facebook nor Twitter has a proper monitoring system and this thing is also expanding the level of hate content. (C.Udanor, Chinatu C.Anyanwu , 2019) A sample of 200 users was randomly chosen from various cities of India. The data was collected through a survey based on the questions related to sensitive tweets and the attitude of users to examine free speech. Through this research, the author found that hate speeches are increasing in India and people are enjoying it. (Iftikhar, et al, 2016) In research, Maina researched the history of Kenya about their political system. He found that hate speech became the reason for violence in Kenya that raised mass killings too. He also said that social media and the internet contributed to this aspect and made it easy for people to spread hate speech.(Maina, 2010)

A study conducted by Raunch and Schanz highlights that people are influenced by the perceptions of the majority opinion in the online environment regardless of their own. According to the research, it is not difficult to provoke online content if it is harsh and against any individual or a radicalized group. (Raunch \& Schanz, 2013) 


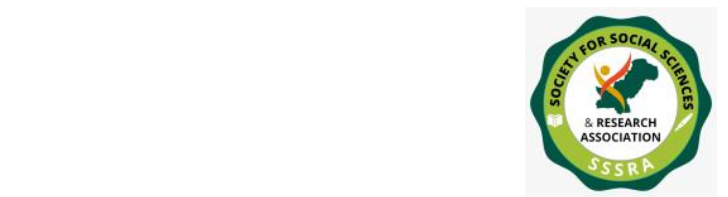

Pak. Journal of Int'L Affairs, Vol 4, Issue 1 (2021)

Hate Speeches on Twitter and Facebook ...

A report published in the New York Times stated Twitter received five requests in Pakistan from Pakistan Telecommunication Authority PTA to block blasphemous content in 2012. As a response, Twitter agreed to block content in Pakistan and it was the first time when Twitter received removal requests from the Pakistani government and companies. The same action has to be needed in the current situation of the South Asian audience. (Masood, 2012).

In December 2018, the Information Minister of Pakistan Fawad Chaudhry accepted the inactiveness of the Pakistan Electronic Crime Act and Federal Investigation Authority (FIA) cyber wing. He also said the government of Pakistan wants the prevention of hate speech and not to curb free speech but we need the support of social media companies' cooperation. Pakistani courts have also sent orders to remove some accounts having unethical content and exhorted violence at the end of 2018. After addressing hate speech, it can be said that hate speeches exist in South Asian society on social media platforms and they are overtly negative. Now, a multi-concerned approach is needed by cybercrime to invigilate hate speeches. It is under the responsibility of major stakeholders to address this lack of legislation. In past years, our many societies are participating in hate speeches most specifically when we see them in terms of political scenarios. (Dawn News Staff Reporter, 2018, October 17)

It has underscored that the development of critical thinking and the challenges in the form of online hateful commentary has to combat because hate speech has been witnessed in the Twitter and Facebook space. No one can deny that hate speech commonly breach the principle of freedom of speech by transporting violent statements drowning political violence or it can be some other kind of violence too. In the era of the contemporary world, the Internet has truly changed the shape of communications and will continue this challenge to handle communications between people. Hate speech is a crime and this crime raises several questions to reflect which must be resolved.

\section{Theoretical Framework:}

This research is based on four theories of Mass Communication which are associated with the findings of the research, below they are discussed. The framing theory was propounded by Gregory Bateson in the year 1972. The framing refers to the activity of thinking related to the news within the familiar context. The literal meaning of framing is how the incidents are presented to the viewers and how the presentation impacts the people. The word frame refers to structuring the information. The framing can be defined as the way the communication process takes place. Framing is an inevitable part of the 


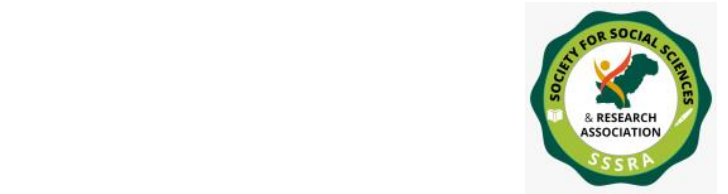

Pak. Journal of Int'L Affairs, Vol 4, Issue 1 (2021)

Hate Speeches on Twitter and Facebook ...

communication process; all humans create their frame in the communication that happens between them. (Framing Theory, 2014, February18).

The agenda-setting theory defines the issues that must be given the public view and attention. When one issue gets a lot of attention then automatically the audience gives more attention to that issue. The mass media is the tool of agenda-setting theory that molds the minds of people and shapes the mindsets of the audience. These days the media agenda is created based on the type of audience and social media is also working to spread agenda on particular issues. As per the researchers' studies, social media bloggers are not bound to follow any rules, they can select any agenda can create content that influences the masses more rapidly. (Brown, 2018)

The Social Responsibility Theory was put forward by Siebert, Peterson, and Schramm in the year 1956. It was developed in the 20th century after the challenges faced by people due to the creation of Libertarian theory that provides absolute freedom to the press. This theory states that the media should play a role in the welfare of the country. Commercial journalism these days gives more value to sensationalism rather than verified news. All of this is done just to get high ratings and sell the news and content so that audience watches the news rather than analyzing it and the same thing is happening on social media these days too.

The propaganda theory was put forward by Edward. S. Herman and Noam Chomsky are one of the books. The theory shares the ways propaganda is practiced in the mass media. According to this model, it helps in better understanding the ways the minds of a common man are molded, along with displaying all social, economic, political attitudes in front of the viewers with the help of propaganda.

\section{Research Methodology:}

The main purpose of this research is to create awareness regarding hate speech that is conducted across social media platforms. We checked the data that we gathered from Facebook and Twitter and analyzed their quality. After general analysis, we depict them in the form of content analysis. We deeply assumed that how this research would be conducted and then on its basis we prepare our discussion. We took Case Study and Content Analysis methods in this research. For this purpose, the collected data would be counted and then depicted in the form of a percentage. To check the ratio of hate speech we used the quantitative method and analyzed the case.

A case study is a research approach that we can use to accomplish a comprehensive 


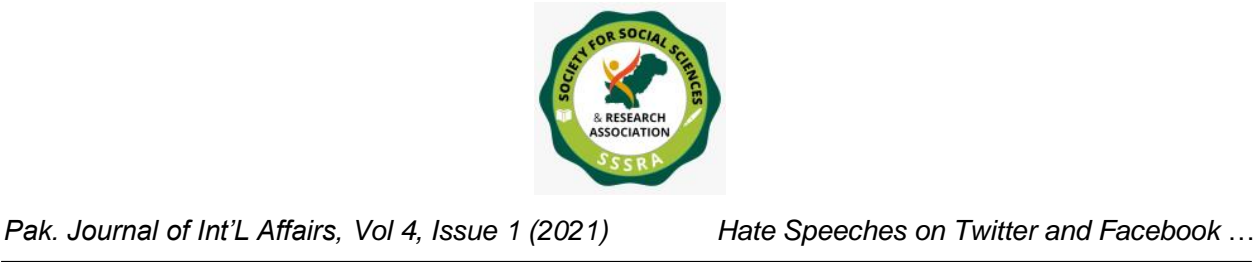

flexible understanding of a confusing issue or matter in the real-life substance. (Crowe, 2011)

This case study method is based on Framing Theory, as we discussed that this theory addresses the core issues of a particular issue. Those issues that drive any kind of agenda mostly created by the media. In the process of framing the cycle eliminate some core aspects. (Scheufele, 1999)

On these aspects, we connect this theory with our research. Based on this theory, we took three frames as tools to calculate the extracted data from Facebook and Twitter. When we'll elaborate on the findings at that time, we'll discuss that how these three tools would work to analyze the data. But let us explain the definition and essence of those tools. The explanation is below:

\section{In Favor:}

The first tool is in favor, in this frame, we separate the people who had favorable opinions about Malala.

\section{Hate Speech:}

The second tool is Hate speech, in this frame, we add the data in the form of numbers that were based on hateful and ugly content against Malala.

\section{Neutral:}

While our third frame is neutral. In this frame, we compute the data that cannot be encompassed in the hate speech or favor section in any case.

Content Analysis is a research tool used to check the data that we collect, it points out the characteristics of messages and is naturalistic in approach. As we have already discussed three frames on which this research is proposed. So, we'll check the three frames in the form of statistical results and then apply content analysis.

Our sources were Twitter and Facebook and the tweets and posts that we found from the social media sites were analyzed properly. So, our research determines that how content analysis uses a combined qualitative and quantitative approach. This research emphasizes that how two different types of data from (Facebook and Twitter) analyze when qualitative and quantitative approaches are used altogether.

Data and Analysis:

To analyze the case study, we used the most prominent hashtags that were used on social media at the time when Malala's case began in South Asia. 


\begin{tabular}{|l|l|}
\hline Frames & Definition \\
\hline In Favor & $\begin{array}{l}\text { Those tweets and Facebook posts that we didn't } \\
\text { consider in hate speech and gave the briefing or favor } \\
\text { to Malala. }\end{array}$ \\
\hline Hate Speech & $\begin{array}{l}\text { Those tweets and Facebook posts in which we found } \\
\text { any kind of hate or brutal phrases. }\end{array}$ \\
\hline Neutral & $\begin{array}{l}\text { Those tweets and Facebook posts were not part of favor } \\
\text { or hate speech. }\end{array}$ \\
\hline
\end{tabular}

We took five hashtags to analyze the topic that how people spoke against her on social media. And they were the most popular hashtags that were used to discuss the personality of Malala.

How people perceived her and how they reacted to her every moment through their words on Twitter and Facebook is the crucial motive of this analysis. Below are the hashtags that were obtained to analyze the case study of Malala Yousufzai and these hashtags were taken since the time this incident began, most were from the year 2011 and are still in the use on social media and all the hashtags that we used to conduct the research were based on random sampling without any specification:

\section{\#malala}

\#istandwithmalala

\#malalaattack

\#iammalala

\#gulmakai

Results and Findings:

\#malala

Results of Tweets:

TABLE: 1

\begin{tabular}{|l|l|l|}
\hline In favor & Hate Speech & Neutral \\
\hline
\end{tabular}




\section{Twitter Results}

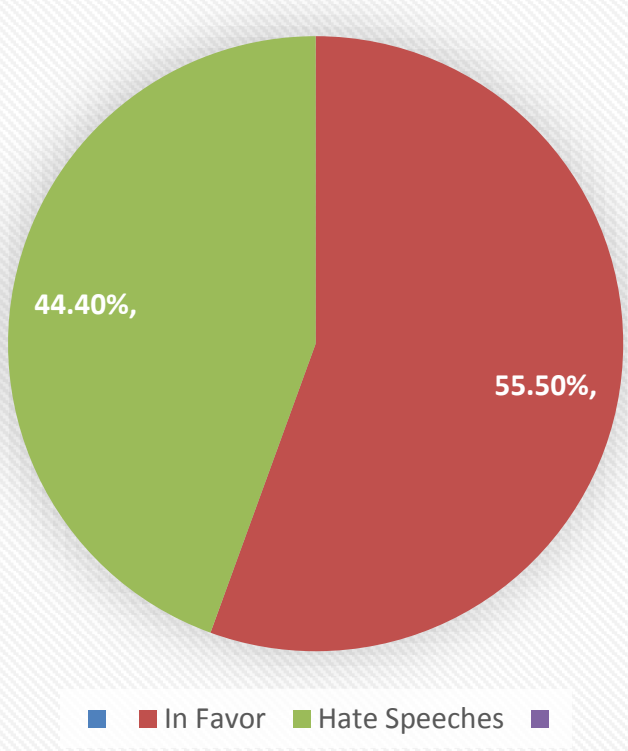

Table 1: According to the table $55.5 \%$ of tweets were positive without any hate speech while, $\mathbf{4 4 . 4 \%}$ were based on hate speeches and no neutral tweet was found.

\#malala

Results of Facebook Posts:

TABLE: 2

\begin{tabular}{|l|l|l|}
\hline In favor & Hate Speech & Neutral \\
\hline $91.6 \%$ & $8.3 \%$ & $0 \%$ \\
\hline
\end{tabular}




\section{Facebook Results}

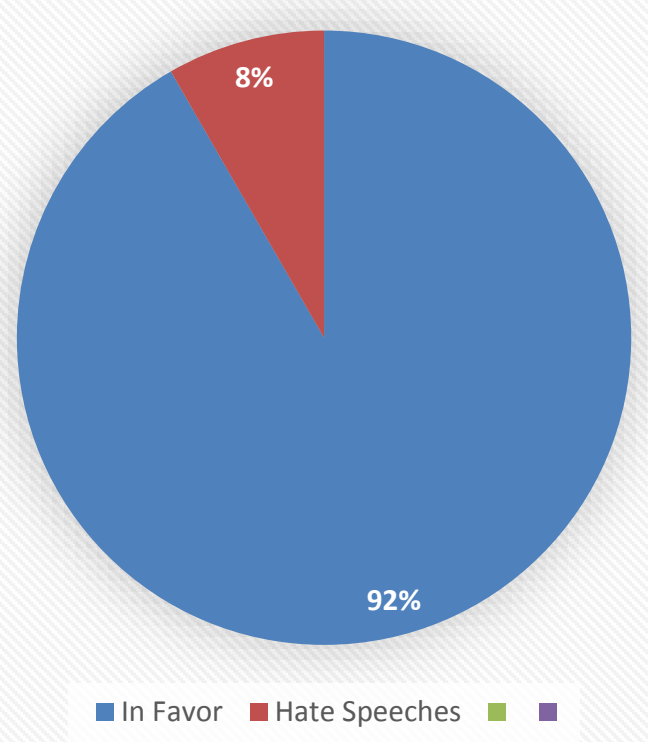

Table 2: According to the table almost $92 \%$ of posts were positive without any hate speech while, $8 \%$ were based on hate speeches and no neutral post was found.

\#istandwithmalala

Results of Tweets:

TABLE: 3

\begin{tabular}{|l|l|l|}
\hline In Favor & Hate Speech & Neutral \\
\hline $98.1 \%$ & $1.8 \%$ & $0 \%$ \\
\hline
\end{tabular}




\section{Twitter Reults}

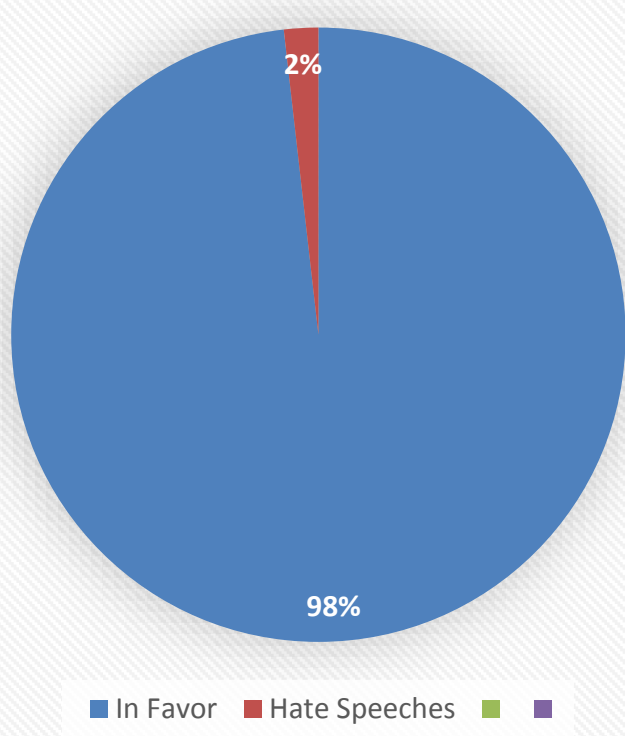

Table 3: According to the table $98 \%$ of tweets were positive without any hate speech while only $2 \%$ were based on hate speeches and no neutral tweet was found.

\section{\#istandwithmalala}

Results of Facebook Posts:

TABLE: 4

\begin{tabular}{|l|l|l|}
\hline In favor & Hate Speech & Neutral \\
\hline $100 \%$ & $0 \%$ & $0 \%$ \\
\hline
\end{tabular}




\section{Facebook Results}

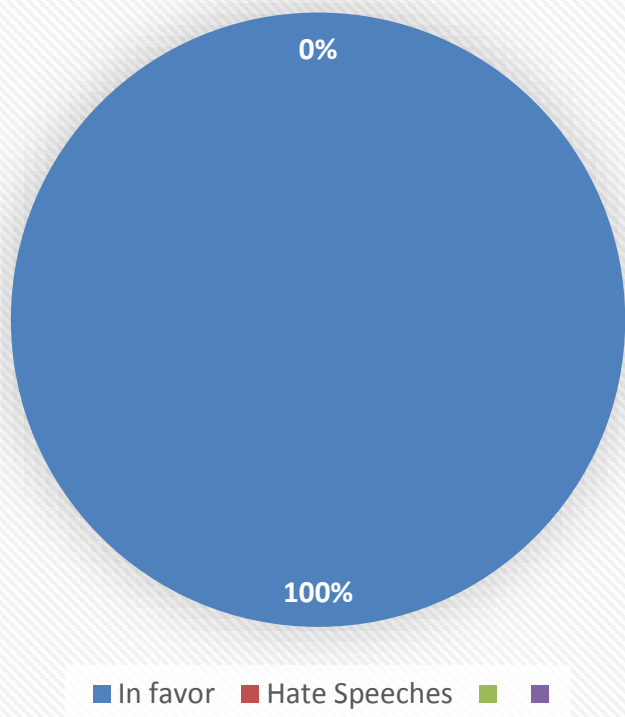

Table 4: According to the table $100 \%$ of posts were positive without any hate speech while no post was based on hate speeches and no neutral post was found.

\section{\#iammalala}

Results of Tweets:

TABLE: 5

\begin{tabular}{|l|l|l|}
\hline In Favor & Hate Speech & Neutral \\
\hline $87.2 \%$ & $12.7 \%$ & $0 \%$ \\
\hline
\end{tabular}




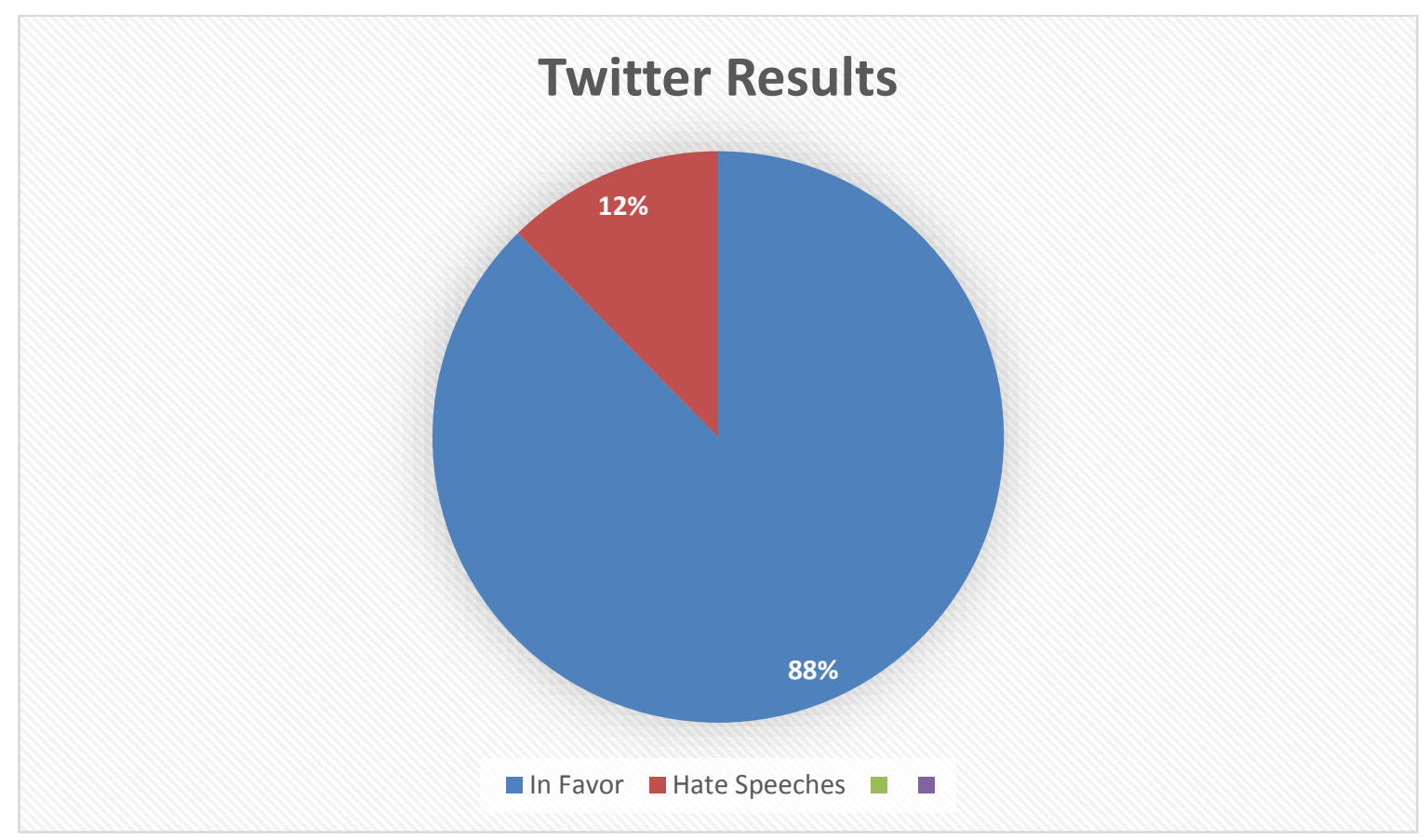

Table 5: According to the table almost $88 \%$ of tweets were positive without any hate speech while $12 \%$ were based on hate speeches and no neutral tweet was found.

\section{\#iammalala:}

Results of Facebook Posts:

TABLE: 6

\begin{tabular}{|l|l|l|}
\hline In favor & Hate Speech & Neutral \\
\hline $100 \%$ & $0 \%$ & $0 \%$ \\
\hline
\end{tabular}




\section{Facebook Results}

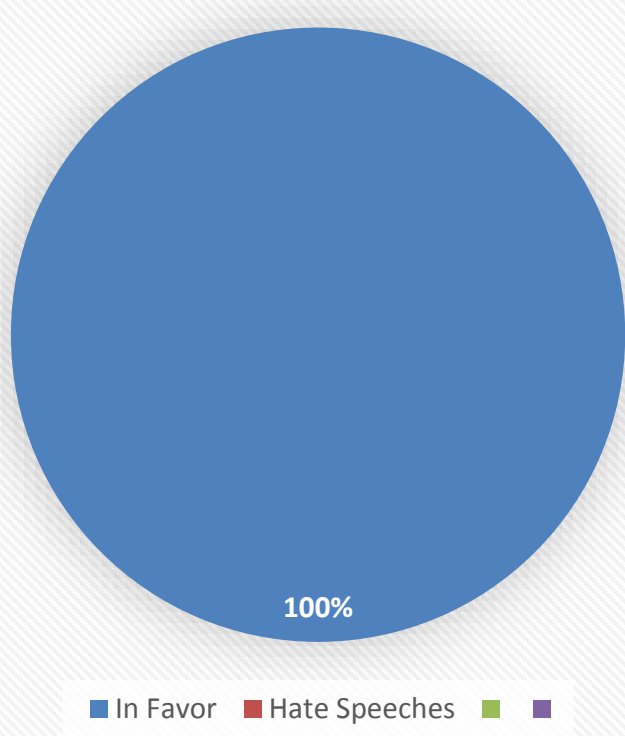

Table 6: According to the table $100 \%$ of posts were positive without any hate speech while no amount of hate speech and no neutral post was found.

\#malalaattack:

Results of Tweets:

TABLE: 7

\begin{tabular}{|l|l|l|}
\hline In Favor & Hate Speech & Neutral \\
\hline $89 \%$ & $10.9 \%$ & $0 \%$ \\
\hline
\end{tabular}




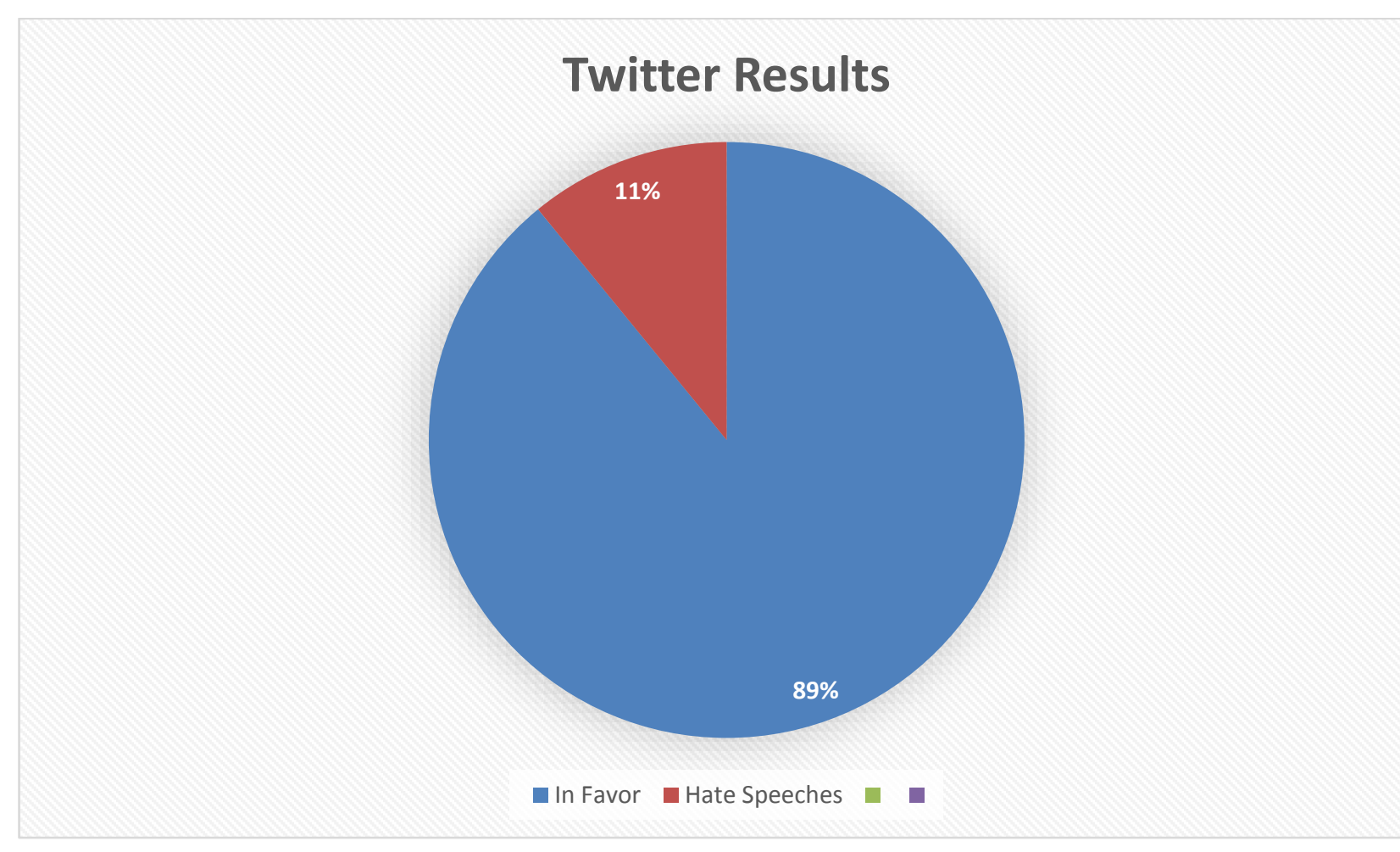

Table 7: According to the table $89 \%$ of tweets were positive without any hate speech while only $11 \%$ were based on hate speeches and no neutral tweet was found.

\#malalaattack:

Results of Facebook Posts:

TABLE: 8

\begin{tabular}{|l|l|l|}
\hline In Favor & Hate Speeches & Neutral \\
\hline $0 \%$ & $0 \%$ & $0 \%$ \\
\hline
\end{tabular}

Table 8: According to the table we didn't find any post that can be considered as a favorable post or based on hate speeches or even neutral. We didn't find any Facebook posts with \#malalaattack. 
\#gulmakai:

Results of Tweets:

TABLE: 9

\begin{tabular}{|l|l|l|}
\hline In Favor & Hate Speech & Neutral \\
\hline $95.5 \%$ & $4.4 \%$ & $0 \%$ \\
\hline
\end{tabular}

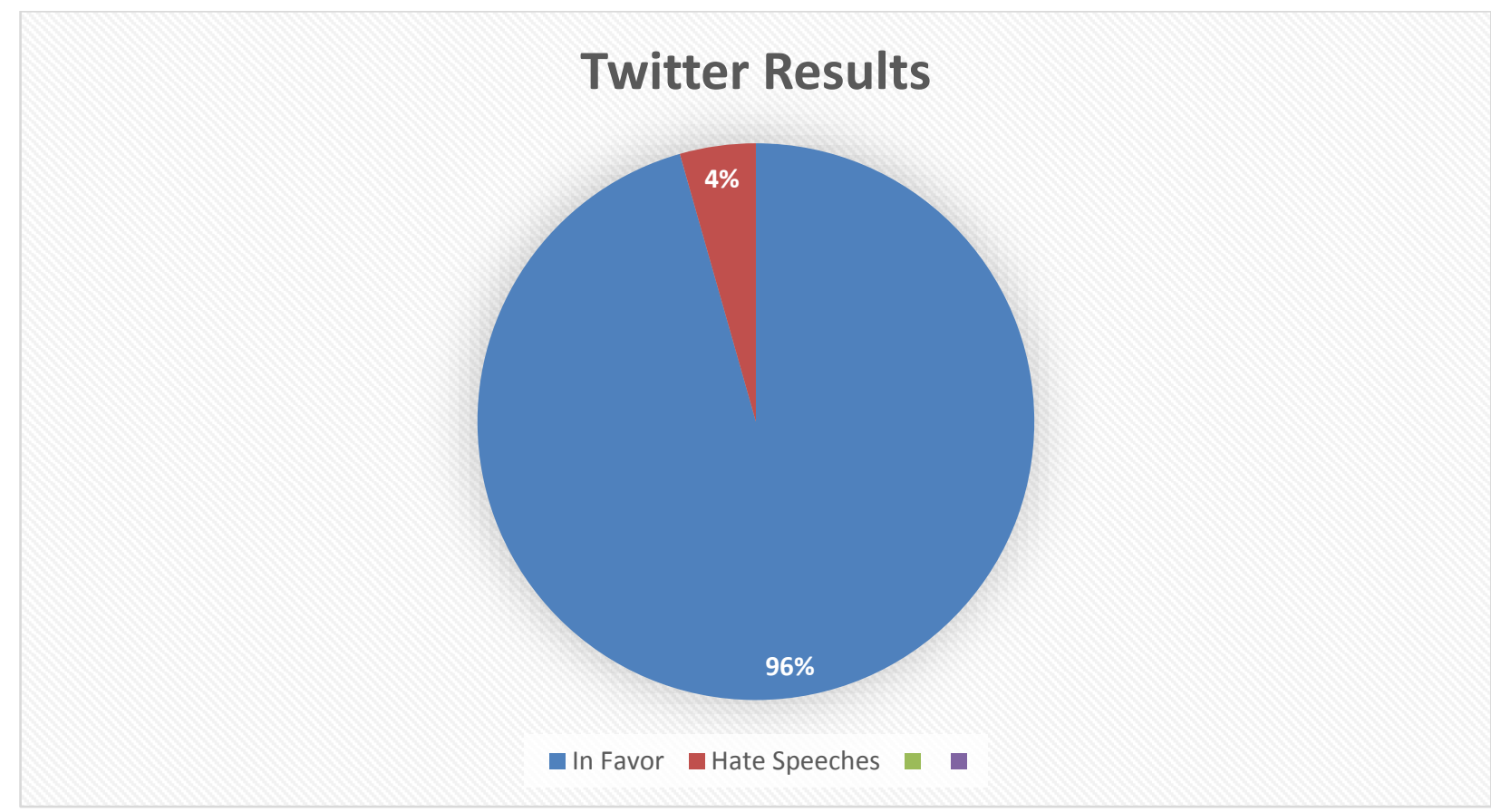

Table 9: According to the table $96 \%$ of tweets were positive without any hate speech while only $4 \%$ were based on hate speeches and no neutral tweet was found.

\#gulmakai:

Results of Facebook Posts:

TABLE: 10

\begin{tabular}{|l|l|l|}
\hline In Favor & Hate Speech & Neutral \\
\hline $95.7 \%$ & $4.2 \%$ & $0 \%$ \\
\hline
\end{tabular}




\section{Facebook Results}

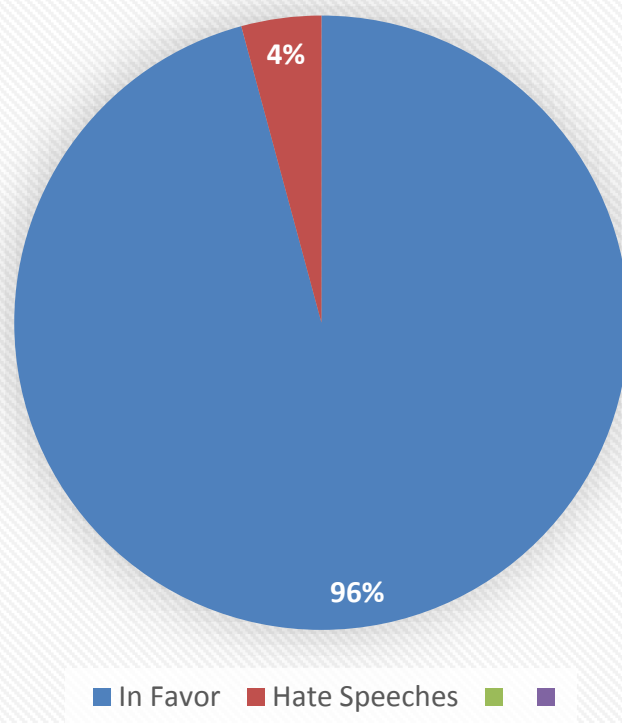

Table 10: According to the table almost $96 \%$ of posts were positive without any hate speech while only $4 \%$ were based on hate speeches and no neutral post was found.

\begin{tabular}{|l|l|l|l|l|l|l|}
\hline \multirow{2}{*}{ Hashtags } & \multicolumn{3}{l}{ Tweets } & \multicolumn{3}{l|}{ Facebook Posts } \\
\hline & $\begin{array}{l}\text { In } \\
\text { Favor }\end{array}$ & $\begin{array}{l}\text { Hate } \\
\text { Speeches }\end{array}$ & Neutral & In Favor & $\begin{array}{l}\text { Hate } \\
\text { Speeches }\end{array}$ & Neutral \\
\hline & & & & & & \\
\hline \#malala & $55.5 \%$ & $44.4 \%$ & $0 \%$ & $91.6 \%$ & $9.09 \%$ & $0 \%$ \\
\hline \#istandwithmalala & $98.1 \%$ & $1.8 \%$ & $0 \%$ & $100 \%$ & 0 & $0 \%$ \\
\hline \#iammalala & $87.2 \%$ & $12.7 \%$ & $0 \%$ & $100 \%$ & 0 & $0 \%$ \\
\hline \#malalaattack & $89 \%$ & $10.9 \%$ & $0 \%$ & 0 & 0 & $0 \%$ \\
\hline \#gulmakai & $95.5 \%$ & $4.49 \%$ & $0 \%$ & $95.7 \%$ & $4.25 \%$ & $0 \%$ \\
\hline & & & & & & \\
\hline
\end{tabular}




\begin{tabular}{|l|l|l|}
\hline Total In-Favor Tweets & Total Hate Speeches' Tweets & Total Neutral Tweets \\
\hline $85.4 \%$ & $14.5 \%$ & $0 \%$ \\
\hline
\end{tabular}

\begin{tabular}{|l|l|l|}
\hline Total In-Favor Posts & Total Hate Speeches' Posts & Total Neutral Posts \\
\hline $98.01 \%$ & $1.98 \%$ & $0 \%$ \\
\hline
\end{tabular}

\section{Discussion:}

With the \#malala, we found an enormous number of tweets on Twitter that include both in favor and hate speeches. For instance, $44.4 \%$ were hate speeches while the rest of $55.5 \%$ were positive without any kind of criticism. As compared to Twitter, Facebook has seen much optimism in this regard. We didn't find any harsh posts on Facebook about her. We found around 91.6\% of Facebook posts In-Favor of Malala while, 9.09\% against her containing hate speeches.

Many hashtags were used in the support of Malala and \#istandwithmalala is one of them. It's signifying the support with Malala. Most of the content that was written with this hashtag was analogous. And if we'll go to analyze it, the same kind of results would be excavated. For instance, when we are going to analyze this hashtag so we saw that almost $98.1 \%$ of tweets were in the favor of Malala, and $1.8 \%$ were against her.

If we determine Facebook results so $100 \%$ of posts with this hashtag were in her favor. People just contend that we are here to stand for her because that physical attack was an attack on education and we purely condemn it. In those posts, people recommended that together we can end the cycle of violence that is halting women to get an education. People mostly delivered in their tweets and posts that we can defy this turmoil and stop it by lifting our voices.

If we enter to examine the \#iammalala so it's apparent that this hashtag was inflated when the book with the same title was published. It's an autobiographical book written by Malala and Christina Lamb in the year 2013, on October 8. If we see the results that we found with the \#iammalala so almost $87.2 \%$ of people were in the favor of her book while $12.7 \%$ oppose it by hate speeches. Most people strongly endorsed her book and spoke that we are Malala. Similarly, when we observe data extracted from Facebook so 


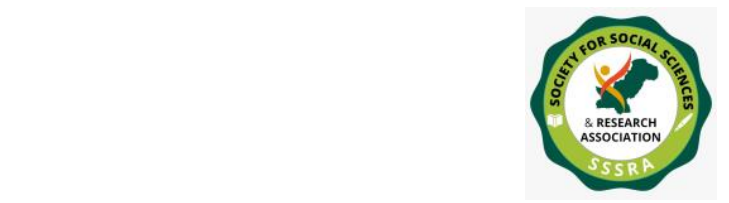

Pak. Journal of Int'L Affairs, Vol 4, Issue 1 (2021)

Hate Speeches on Twitter and Facebook ...

we found $100 \%$ of posts with the hashtag were in her favor. In those posts, people appreciate her book and wrote that this book emphasizes her uniqueness.

When we see the \#malalaattack so people most of the time spoke in her vogue and condemned her attack. So, the hashtag appears to be positive with $89 \%$ tweets in her favor and $10.9 \%$ against her. Although her attack with this hashtag wasn't seen on Facebook with any kind of post.

When we go to extract data from the tweets and Facebook posts of the \#gulmakai so we found that $95.5 \%$ of tweets were in the favor of hashtags and $4.49 \%$ were hate speeches. If we discuss Facebook posts, so those who were in her favor in Facebook posts gave affection to the film and said that it's an enormous credit to Malala for the virtue of education and her desire that she's doing to reach out to her destination. Only $4.25 \%$ of posts delivered hate speeches and the rest of the $95.7 \%$ depicted the recommendation towards this movie.

\section{Conclusion}

Hate speech in online communication can include abusive language and cyberbullying. For this motive, offensive communication can be used against an individual or group. Such words or phrases in Facebook posts and tweets with the uploading of images or videos to provoke people to react badly can be counted in hate speech. It can be exchanged to anyone who's opposing your impression or omitting your post or comments. Although it's not legal to outrage someone by your violent words nowadays it's common on social media. If your like or dislike is distinct concerning any special case so the others who don't appraise your thoughts would be abused.

Sometimes this kind of hate speech also dominates you to face physical violence. Sometimes it also happens because people candidate themselves as they are expressing their opinion or belief and it can be against anyone though there's no boundary to express freedom of speech in a democratic country.

According to Article 9 of human rights, we have the right to express our opinion and express them freely. For that, we can express our views through television, radio, published articles, the Internet, or social media. The Human Rights Act 1968 protects human rights but we have also the duty to respect other people's rights. As everyone has the right to being protected from discrimination and violence. If we correlate this Act with our current study so everyone needs to think about it while abusing or responding to someone on social media. Our right to freedom of speech doesn't allow us to threaten or 


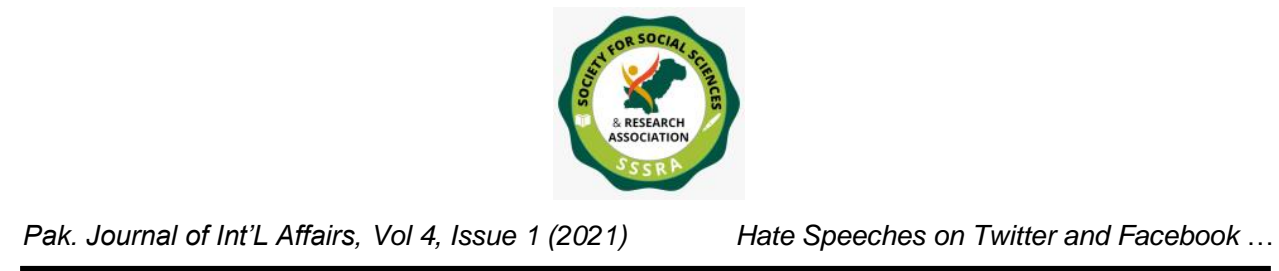

pass hate to anyone. Sometimes these hate incidents add up or reach criminal acts. Nowadays because of the extensive use of social media hate speech is uplifting so somewhere it is also reaching imprisonment.

While conducting our research we found many news articles to uncover hate speech as a crime so, we also found some cases in which the criminals committing hate speeches faced sentences.

The purpose of this study was to examine the proportion of hate speeches in South Asia on the platform of social media and through them how the attitudes of people change. Basically, from our overall results, we concluded that around $85.4 \%$ of tweets were in the favored frame while $14.5 \%$ were in the frame of hate speeches. Contrary, if we evaluate the results determined from Facebook posts, so $98.01 \%$ of posts became the part of InFavor frame while $1.98 \%$ were termed as hate speeches.

We have already been discussed that how this case received hate speeches in South Asia. Another question is that how hate speech is changing the beliefs and attitudes of South Asian society. We also determined that Online hate speech is destroying societies and altering them into a stereotype, with the current analysis of the research it is clear that how South Asian society is going to disrupt itself bypassing the hateful content on social media. Due to excessive usage of social media now the people do not work to verify the cases. For example, if we heard that Malala's incident is pre-planned and she's a Jewish agent so we aren't going to research it. The people who blindly follow others' thoughts on social media started threatening her, they accused her of getting involved in the antiIslam lobby. Even there's no actual evidence against her but after watching frequent tweets and posts against her they claimed her like a culprit.

We also researched that online hate speeches are a cause of promoting extremism in South Asian society, it is general that when two parties are in mortal conflict with each other so they consider the other one wrong and nasty. They share a bitter opinion about each other on every possible discussion. Such notions make people extremist in the favor of their favorite or likable person and hatred against rival party or person. These thoughts ask people to do controversial speeches and it was cleared in the analyzed results of Malala's case study. In many societies, unlimited hate speech spread chaos and people easily turn into extremists.

In South Asia, the main vector of such hateful content that leads to extremism is Twitter and Facebook. It can also be said that the results of all this case briefed that South Asian society isn't working to put a balance between the country's superiority prestige and the 


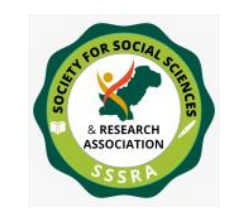

Pak. Journal of Int'L Affairs, Vol 4, Issue 1 (2021)

Hate Speeches on Twitter and Facebook ...

upholding of free speech. They are standing on the philosophy of radicalization and spreading violent extremism on social media.

To understand the context of the resulting data, we have visited many articles in which hate speech was assumed. While in our research we found that hate speech emerges in the form of organized campaigns targeting their opposed political leader or person or scenario and somehow target another person based on his beliefs. A lot of hatred material was frequently attacked by the opponents of Malala and it is still rising in South Asia on daily basis as our audience love to debate on such kind of complex scenarios.

This research measures the instances of effects of social media war and its challenges on the country's cybersphere. The function of social media has lost somewhere. Active Twitter users manipulated news rather than performing the function of disseminating news for the audience or those who follow them. In the tweets and comments section, the actual content was misshapen and reformed from its original form. Whenever flakes are produced on a large scale, they always bring a lot of negative responses, and without strong pieces of evidence, it happened during the Malala case. It further briefs that a single word or combination of words are used to play greatly with the mind of people to impose their ideology into others' brains and change their perceptions too. During research analysis, we also found that when a person published a certain tweet or Facebook post in the favor of his or her favorite character and opposes his or her opponent so his tweet or post is immediately liked, shared, and retweeted by the same supporters of his favored character.

We also concluded that to satisfy themselves people use media sources to update and react to the recent trending to do the same and it mostly happens on the platform Twitter. According to studies, Twitter's two-way nature attracts people to feel socially connected, and then people use social sites to feel more and more contentment through the posting of hate speeches in their tweets. According to the first online hate speech report on Pakistan only $1 \%$ of hate speech has been punished in the form of criminal activity. Whether a report published on the Reuters website in November 2018 draws something different. It said that the warnings which have been sent to many Twitter users that how online speeches are being regulated for social media users who are used to voice their stance. Even though in some of the exceptional cases Twitter uses its censorship policy in Pakistan. So, in the end, we can say that as much we explore social media, we'll find that how much online hate speeches are prospering exaggeration in the society and whirling people into extremists by disrupting peace and harmony of the society. 


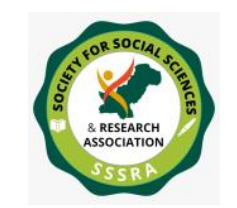

Pak. Journal of Int'L Affairs, Vol 4, Issue 1 (2021)

Hate Speeches on Twitter and Facebook ...

\section{References:}

Abdullahi, A. H. Hate Speech, Twitter and 2019 Election: Analysis of Tweeting Habits of Selected Politicians in Kaduna State.

Ahmad, I. (2018). The History of Social Media [Infographic]. Social Media Today. https://www.socialmediatoday.com/news/the-history-of-social-media-infographic$1 / 522285 /$

Apuke, O. D. (2017). Quantitative research methods: A synopsis approach. Kuwait Chapter of Arabian Journal of Business and Management Review, 33(5471), 1-8.

Arowolo, O. (2017). Understanding framing theory. Lagos State University: Lagos, Nigeria.

Blakemore, B. (2016). Policing cyber hate, cyber threats and cyber terrorism. Routledge.

Brown, J. (2018). Is social media bad for you? The evidence and the unknowns. Future. https://www.bbc.com/future/article/20180104-is-social-media-bad-for-you-theevidence-and-the-unknowns

Cassidy, W., Jackson, M., \& Brown, K. N. (2009). Sticks and stones can break my bones, but how can pixels hurt me? Students' experiences with cyber-bullying. School Psychology International, 30(4), 383-402.

Chao, E. C. (2015). The-Truth-About-Islam. com: Ordinary Theories of Racism and Cyber Islamophobia. Critical Sociology, 41(1), 57-75.

Crowe, S., Cresswell, K., Robertson, A., Huby, G., Avery, A., \& Sheikh, A. (2011). The case study approach. BMC medical research methodology, 11(1), 1-9.

Dawn News Staff Reporter, (2018, October 17). PTA offers to transfer monitoring of electronic crimes to FIA. Dawn News, https://www.dawn.com/news/1439534

Edosomwan, S., Prakasan, S. K., Kouame, D., Watson, J., \& Seymour, T. (2011). The history of social media and its impact on business. Journal of Applied Management and entrepreneurship, 16(3), 79-91.

Enarsson, T., \& Lindgren, S. (2019). Free speech or hate speech? A legal analysis of the discourse about Roma on Twitter. Information \& communications technology law, 28(1), 1-18.

Framing Theory. (2014, February 18). Mass Communication Theory. https://masscommtheory.com/theory-overviews/framing-

theory/\#: : text=The $\% 20$ concept $\% 20$ of $\% 20$ framing $\% 20$ is, within $\% 20 \mathrm{a} \% 20$ field $\% 20$ of\%20meaning.

Gelashvili, T. (2018). Hate Speech on Social Media: Implications of Private Regulation and Governance Gaps. 


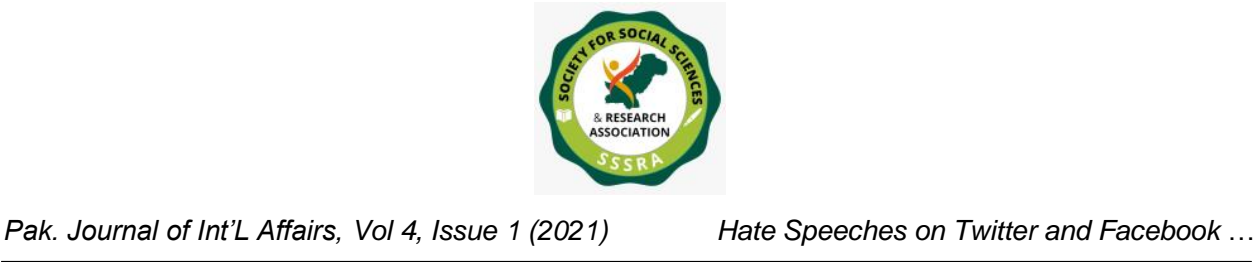

Iftikhar, A., Roshan Raini, L. and Faizia, S. (2016), Free vs hate speech on social media: the Indian perspective, Journal of Information, Communication \& Ethics in Society, 14(4), pp. 350-363, available at: https://doi.org/10.110/jices-06-2015-0016.

Levin, B. (2002). Cyberhate: A legal and historical analysis of extremists' use of computer networks in America. American Behavioral Scientist, 45(6), 958-988.

Levin, B. (2002). Cyberhate: A legal and historical analysis of extremists' use of computer networks in America. American Behavioral Scientist, 45(6), 958-988.

Maina, K. (2010), "Speech, power and violence: hate speech and the political crisis in Kenya", available at: www.ushmm.org/m/pdfs/20100423-speech-power-violencekiai.pdf

Masood, S. (2012). Pakistan Blocks Access to Twitter Over Cartoon Contest. The New York Times. https://www.nytimes.com/2012/05/21/world/asia/pakistan-blockstwitter-over-cartoon-contest.html

More Hate Speech on Twitter Than on Facebook in Pakistan: Study. (2018). The Express Tribune. $\quad$ https://tribune.com.pk/story/1764267/1-hate-speech-twitter-facebookpakistan-study.

Nowak, E. (2016). Agenda-setting theory and the new media. Studia Medioznawcze Media Studies, 3(66), 11-24.

Okoro, N., \& Santas, T. (2017). An appraisal of the utilisation of social media for political communication in the 2011 Nigerian presidential election. African Research Review, 11(1), 115-135.

Pakistan's new internet laws tighten control over social media. DW News https://www.dw.com/en/pakistans-new-internet-laws-tighten-control-over-socialmedia/a-52375508

Propaganda Model. In Communication Models, Political Communication. Communication Theory. https://www.communicationtheory.org/propagandamodel/

Rauch, S., and K. Schanz. 2013. "Advancing Racism With Facebook: Frequency and Purpose of Facebook Use and the Acceptance of Prejudiced and Egalitarian Messages." Computers in Human Behavior 29 (2): 610-15.

Roels, J. (2017). The Battle against Hate Speech and Freedom of Expression Online. Charles University in Prague Faculty of Law Research Paper No.

Scheufele, D. A. (1999). Framing as a theory of media effects. Journal of communication, 49(1), 103-122.

Starman, A. B. (2013). The case study as a type of qualitative research. Journal of Contemporary Educational Studies/Sodobna Pedagogika, 64(1). 
The Agenda-Setting Theory in Mass Communication. Alvernia University. https://online.alvernia.edu/articles/agenda-setting-theory/

Udanor, C., \& Anyanwu, C. C. (2019). Combating the challenges of social media hate speech in a polarized society. Data Technologies and Applications.

Udoh-Oshin, G. (2017). Hate Speech on the Internet: Crime or Free Speech?. Undergraduate Honors College Theses 2016-. 9. https://digitalcommons.liu.edu/post_honors_theses/9

Uzuegbunam, C. E. (2015). The Social Responsibility Theory of The Press: A Contemporary

Review. https://www.researchgate.net/publication/280310541_THE_SOCIAL_RESPONSIB ILITY_THEORY_OF_THE_PRESS_A_CONTEMPORARY_REVIEW

Zain, N. R. B. M. (2014). Agenda Setting Theory. International Islamic University Malaysia. 